\title{
Are Mathematics Curricula Harmonizing Globally Over Time? Evidence from TIMSS National Research Coordinator Data
}

\author{
Stefan Johansson ${ }^{1 *}$, Kajsa Yang Hansen ${ }^{1,2}$ \\ ${ }^{1}$ Department of Education and Special Education, University of Gothenburg, SWEDEN \\ ${ }^{2}$ Department of Social and Behavioural Studies, University West, SWEDEN
}

Received 29 March 2018 - Revised 30 May 2018 - Accepted 6 September 2018

\begin{abstract}
Given the impact of international large-scale assessments (ILSAs) on policy-making in different educational systems around the world, this study aims to examine whether national mathematics curricula in different educational systems harmonize over time. Data from the Trends in International Mathematics and Science Study (TIMSS) is used to explore this issue. In addition to background questionnaires given to students, teachers and schools, a curriculum questionnaire was completed by each national research coordinator (NRC) in all participating countries in each TIMSS cycle. In the present study, data from 2003, 2007, 2011 and 2015 was used. The analyses focused on the information about the extent to which the national mathematics curriculum covered certain topics in the subdomains of mathematics tested in TIMSS Grade 8. Growth curve modeling and latent profile analyses were applied to uncover the development trend and countries' unobserved profiles in mathematics content domains of Number, Algebra, Geometry, and Data. Three clusters of countries were identified. Most countries belonged to the same profile in the later cycles of TIMSS. The study found indications of a general harmonization with respect to number of topics covered in countries' curricula over time, thus contributing to discussions of policy implications of a global curriculum.
\end{abstract}

Keywords: TIMSS, world curriculum, intended curricula, harmonization convergence

\section{BACKGROUND}

In a highly globalized world, the acquisition of knowledge and skills for civic success becomes increasingly important, not least since claims have been made suggesting that economic growth follows improved knowledge among citizens (Hanushek \& Woessman, 2012, 2016; Sahlberg, 2006; for a discussion, see Komatsu \& Rappleye, 2017). The increasing number of countries participating in the international large-scale assessment studies (ILSA) in the past two decades may be viewed as a consequence of a desire to compare and learn lessons from other school systems as a means of facilitating improvements for national school systems (Hegarty, 2014; Johansson, 2016). The results of ILSAs have also gained a prominent position in political, professional and public discourse (e.g., Hopmann, Brinek, \& Retzl, 2007). Knowledge generated about education seems to play an increasingly important role in decision-making and school reforms (e.g., Gorur \& Wu, 2014; Grek 2009, 2013; Ozga, 2012).

Consequently, results from ILSAs can provide the catalysts for educational change, and inspire the search for models 'imported' from other countries which might solve perceived problems. In such policy 'borrowing', educational systems with perceived success attract greater external attention than others, even though processes of decision-making, implementation and internalization all involve considerable transformations of the 'borrowed' policy (Phillips \& Ochs, 2004; Winstanley, 2012). Despite the perceived value of borrowing successful educational strategies, potential drawbacks have also been observed; some authors claim that countries lose their own uniqueness, innovativeness and creativity (Pettersson, 2008; Wiseman, Astiz, \& Baker, 2013; Zhao, 2012). Given various policy recommendations based on, for example, OECD reports, it may be tempting to look at successful

(C) 2019 by the authors; licensee Modestum Ltd., UK. This article is an open access article distributed under the terms and conditions of the Creative Commons Attribution License (http://creativecommons.org/licenses/by/4.0/). \Stefan.johansson@gu.se (*Correspondence) kajsa.yang-hansen@ped.gu.se 


\section{Contribution of this paper to the literature}

- This paper explores under-used TIMSS-data from National Research Coordinators to shed light on curricula coverage across countries over time.

- There are country differences between subdomains of mathematics with respect to their coverage in mathematics curricula. All countries include a high degree of arithmetic skills. However many countries include statistics and geometry to a lesser degree.

- There are indications of a general trend of harmonizing, in that countries' curricula become increasingly similar with respect to coverage of mathematics topics .

nations' curricula and reform domestic curricula accordingly. However, what works in one country need not necessarily work in another where there is a different context, tradition, language and culture.

\section{Developing Curricula}

The development of curricula and educational systems around the world is a contentious issue, and an area of research mainly in the field of the sociology of education (see, for example, Benavot, Cha, Kamens, Meyer, \& Wong, 1991; Meyer, Kamens, \& Benavot, 1992; Meyer, Boli, \& Ramirez, 1997). How knowledge and skills are transmitted to the masses raises questions not only about school curricula, but also about how societies are formed. There are different theories of how educational systems throughout the world develop their curricula - often highlighting the differences and similarities across countries. According to functionalist theories, there should be differences as regards curriculum in different societies. While in more developed societies, there should be more focus on mathematics, natural sciences and social sciences, less developed societies should place greater emphasis on instruction in vocational subjects and domestic science. As societies develop, there should be an increased focus on modern subjects. Further, national curricula vary by the level of socioeconomic development, and because socioeconomic differences are quite stable across countries, curricular differences will be too. Historic theories suggest diversity in national curricula among countries or world regions, and a substantial degree of stability over time (see, for example, Benavot et al., 1991). However, less empirical evidence has been brought forward to support these theories. Meyer and colleagues at Stanford $(1992,1997)$ propose the idea that curricula are closely tied to standardised world models and globalisation, and that as a consequence, national curricula will become increasingly similar over time. Dale $(1999 ; 2000)$, on the other hand, argues that countries tend to converge regionally, not globally. Some empirical findings have also confirmed that this tends to be the case, at least in terms of the "attained curricula", i.e. the outcome level of a national curricula (Rutkowski \& Rutkowski, 2009).

Within the organisation the International Association for the Evaluation of Educational Achievement (IEA), a three-level model of the context and components of the school curriculum was developed in order to shed light on the different levels of curricula, which are important for students' learning opportunities (e.g., Keeves, 1972; Robitaille \& Garden, 1989). At the level of the educational system (the school-system, the educational region, the school district) there is a set of intentions for the curriculum. There are goals and traditions as well as influences from the national educational and social context that help shape the character of the curriculum. This collection of intended outcomes, along with course outlines, official syllabi, and textbooks, together form an intended curriculum. The second level deals with the classroom setting, within which the mathematics content becomes implemented or translated into reality by teachers. Seen this way, teachers and classroom conditions are central to the educational process and to the ways in which mathematics content is introduced, and children's attitudes towards mathematics are formed. The final level of this model represents the attained curriculum. After a given period of time at school, the student has acquired a body of knowledge, and acquired certain attitudes toward the subject.

\section{Empirical Findings of Curricula Harmonization}

Several different methods and materials have been used to address questions of globalization in education. Text analyses of official policy documents, curricula and textbooks, for example, has been used to reflect the changes in the intended curricula in different countries over time (Meyer et al., 1992; Benavot et al. 1991; Baker \& LeTendre, 2005; Bromely, et al. 2011). Shedding light on curricular development, research has focused on time spent on different subject domains in different countries (Schmidt et al., 1997; Baker \& LeTendre, 2005; Stacey et al., 2018). Large-scale data has been used to explore performance patterns across countries, i.e. asking what students know instead of how much they know (Rutkowski \& Rutkowski, 2009). In the following section, some of these findings, mainly as regards aspects of intended curricula, are presented.

Bromely, Meyer, and Ramirez (2011) addressed the issue of intended curricula by carrying out a longitudinal comparison of textbooks from countries around the world. More specifically, they explored the rise of student- 
centered education in different regions of the world, finding a substantial growth over time which reflected changed world models. The increases seem to be intensified by the often-noted global shift in instruction away from history to social studies and civics, and by the increased foci of curricula on social issues and problems of interest to the student. Some differences between world regions were also demonstrated. Textbooks in Western countries were more student-centered than those of Eastern European countries. In Latin American countries, textbooks were even more student-centered.

In association with TIMSS 1995, Schmidt et al. (1997) studied curricular intentions and found considerable crosscountry variation. However, with increasing globalization, it is possible that educational systems tend to be more homogenous over time. In the TIMSS 2015 Encyclopaedia (Mullis, Martin, Goh, \& Cotter, 2016), it is demonstrated that countries show more similarities than differences, although there is a wide diversity of the countries participating in TIMSS 2015. Most countries, for example, specified major content domains, such as algebra. It should however be noted that during the 20 years of TIMSS, nearly all countries have implemented curricular reforms in mathematics.

A recent report by Stacey et al. (2018) using data from National Research Coordinators in five TIMSS cycles investigated how globalization has impacted on science curricula. Their focus was on the aspects of intended curricula and they explored, among other things, whether there had been changes in science curricula over the last 20 years, and whether there was a trend of science curricula becoming increasingly similar across countries. Their analysis, which focused on both fourth and eighth grade students, investigated whether or not a number of different science topics in several subjects (i.e. biology, chemistry, physics) had been covered in countries' curricula. For this purpose, they used data from NRC's in 1999 (2003 for $4^{\text {th }}$ graders), 2007 and 2015. Results showed a considerable variation among countries in terms of the number of topics covered, and changes made to the science curricula across the period 1999-2015. Via cluster analysis and discriminant analysis, Stacey et al. (2018) however identified two clusters of countries with different coverage (high-low) with respect to the available science topics. Between the TIMSS administrations in 2007 and in 2015, a large share of countries in grade four, as well as in grade eight, moved to the group with higher coverage of science topics. This result provides support for the hypothesis that science curricula are becoming increasingly similar across countries, and that this trend may be particularly true for grade eight.

\section{Aim of the Present Study}

In several previous studies, textbooks have been viewed as providing a supplementary, supporting reflection of curricular intentions. Textbooks are thus viewed as a primary bridge between curricula intention and curricula implementation, and between a national education agency and the teacher in the classroom. While care must be taken in interpreting textbook data - given the varying status and use of for textbooks - research conducted in many countries indicates the enormous influence textbooks have on student achievement. Nonetheless, neither curriculum guides nor textbooks should stand alone as the sole source of data for the curriculum analyses. In fact, ILSA data may provide a unique possibility to explore the development of different school-systems; this is because in many countries subject experts have provided rich information on the school-systems and indented curricula for particular subjects. The current study relies on survey data from national research coordinators (NRC) in TIMSS to address the issue of intended curricula. Digesting textbook data from many countries is a time-consuming task for a single researcher. That is why making use of the already existing data from IEA could be an advantage. Furthermore, few studies have taken advantage of the rich national curriculum data from IEA, and, to the best of our knowledge, none using mathematics curriculum data.

In studying curricula change in item-level research, rather than investigating broader content areas, it may not be fully possible to capture curricula change (curricula do not cover test items, but they refer to more general constructs such as Pythagoras' theorem or geometry). For this reason, the approach using single topics employed in the study by Stacey colleagues (2018) may be somewhat too detailed to find curricular changes at the global level in mathematics (although in science more noticeable movements are likely to be present, for example relating to the coverage of topics such as climate change). In order to approach curricular change, larger streams of knowledge, such as the subject content domains in mathematics (e.g., algebra, data, geometry, and number) therefore need to be focused upon.

Against this background, the overall aim of the study is to explore the development of curricular coverage across countries and time in mathematics, and to attempt to identify indications of harmonizing processes in countries' intended curricula coverage over a 12-year period. To this end, the following questions guided the investigation:

a) Are countries covering more math topics in their curricula over time?

b) Are countries becoming increasingly similar with respect to their curricula coverage?

c) Are curriculum revisions more frequent in TIMSS 2011 and 2015, compared to earlier TIMSS studies? 


\section{DATA AND METHOD}

Directed to the National Research Coordinators (NRC), the Curriculum Questionnaire (CQ) in TIMSS addresses the structure and content of national curricula. It is data from this questionnaire which forms the empirical base of the current study In total, four cycles of IEA TIMSS assessments on mathematics in grade 8 were used (2003, 2007, 2011 and 2015). One general part of CQ concerns the requirements for being a teacher in each respective country, and includes subject modules about mathematics and science. Surprisingly, given the extensiveness of the questionnaire, the data has not been frequently taken advantage of in secondary analyses. To investigate the possible shift of intended mathematics curricula across countries and over time, we used questions about countries' curricula coverage in the mathematical domains. In TIMSS 2003, 52 countries participated in the study, including benchmarking participants. In TIMSS 2007, the number increased to 64, while in 2011 it dropped to 59 countries. In 2015, only 46 countries participated. Most countries have participated in TIMSS on three or four occasions. It shall be recognized that the number of developing countries has increased in the more recent cycles. Nevertheless developed countries remain over-represented. For these countries, it is possible to follow their trend in a more comprehensive manner. While this may limit the generalisability of the conclusions, data comes from a large set of diverse countries.

The overarching question According to the national mathematics curriculum, what proportion of grade 8 students should have been taught each of the following topics or skills by the end of grade 8? comprised several subdomains. As subdomain categories vary slightly across TIMSS cycles, the topics contained within them also varied somewhat. In general, there were more topics listed in the first TIMSS cycles. In the 2003 cycle, the range of topics was very comprehensive, including more than 40 different topics, while in 2015 there were only 20 topics that the NRCs were asked to consider. We allowed the most recent subdomain categorization in TIMSS ${ }^{1}$ (Number, Algebra, Geometry and Data and Chance) to serve as the reference for our comparison, this being because corresponding items could be found in the previous assessments.

In Table 1, the items relating to different mathematics subdomains from 2015 are presented. Corresponding items were also present in 2003, 2007, and 2011. However, the wordings of some items were different. These differences were terminological, rather than substantive. The respondent NRCs had three response alternatives to the question above: (0) Not included in the curriculum through grade 8 (1) All or almost all students (2) Only the more able students (top track). Because the use of category 2 was not present for many of the items, this response was recoded and collapsed into the category one (1).

\footnotetext{
${ }^{1}$ For sake of simplicity we hereafter refer to subdomain Data while the TIMSS administration denotes this subdomain Data and Chance. In the 2003 assessment, subdomain Measurement was included as well. Some items in this category could later be found in category Geometry.
} 
Table 1. Mathematics topics

According to the national mathematics curriculum, what proportion of grade 8 students should have been taught each of the following topics or skills by the end of grade 8 ?

\begin{tabular}{l}
\hline Number \\
a) Computing with whole numbers \\
\hline b) Comparing and ordering rational numbers \\
\hline c) Computing with rational numbers (fractions, decimals, and integers) \\
\hline d) Concepts of irrational numbers \\
\hline e) Problem solving involving percents or proportions \\
\hline Algebra \\
\hline a) Simplifying and evaluating algebraic expressions \\
b) Simple linear equations and inequalities \\
\hline c) Simultaneous (two variables) equations \\
\hline d) Numeric, algebraic, and geometric patterns or sequences (extension, missing terms, generalization of patterns) \\
\hline e) Representation of functions as ordered pairs, tables, graphs, words, or equations \\
f) Properties of functions (slopes, intercepts, etc.) \\
\hline Geometry \\
a) Geometric properties of angles and geometric shapes (triangles, quadrilaterals, and other common polygons) \\
\hline b) Congruent figures and similar triangles \\
\hline c) Relationship between three-dimensional shapes and their two-dimensional representations \\
\hline d) Using appropriate measurement formulas for perimeters, circumferences, areas, surface areas, and volumes \\
\hline e) Points on the Cartesian plane \\
f) Translation, reflection, and rotation \\
\hline Data and Chance \\
\hline a) Characteristics of data sets (mean, median, mode, and shape of distributions) \\
\hline b) Interpreting data sets (e.g., draw conclusions, make predictions, and estimate values between and beyond given data points) \\
\hline c) Judging, predicting, and determining the chances of possible outcomes \\
\hline
\end{tabular}

TIMSS 1995 data was not included. This was because the main question in this study was phrased as a topic being "focused or not", and different from the wording of a topic being "covered or not" that is used in the later TIMSS studies Consequently, we focus on comparisons between TIMSS 2003, 2007, 2011 and 2015.

Furthermore, we also used information about revisions of the mathematics curricula: Is the mathematics curriculum currently being revised? This question is also available from all four TIMSS studies, and can facilitate exploration as to whether there are any general trends emerging in a particular country.

\section{Analytical Methods and Procedure}

Based on the 20 topics available in TIMSS 2015, we recoded the corresponding items in the previous cycles to the same variable names, and merged the datasets of different years into a common data file. The common data file comprises scores for all countries that participated in at least one TIMSS cycle since 2003. The file comprised 221 country-by-cycle cases. We saved an ID for 'cycle' in order to be able to trace any curricular changes. This file was used for latent class analyses. In a later step, we restructured the file of 221 cases to achieve a dataset that contains 80 countries with repeated measures of content coverage variables for each cycle. We used Latent Growth Curve Modeling and Latent Profile Analysis techniques to tackle the information about mathematics curricula provided from the NRC's. The analyses were carried out in Mplus 8 (Muthén \& Muthén, 1998-2017).

\section{Latent growth curve modeling}

Since the trend of curriculum harmonization is the focus in the current study, we employed latent growth curve modeling (LGCM). This incorporated latent variables (i.e., growth factors) to account for the structural relations among the repeated observations of the content coverage in mathematics across country and time. The LGCM technique estimates two growth factors, namely an intercept factor and a slope factor, to capture the development of content coverage across time in different school systems. It assumes, for example, that the mathematics content coverage in all countries develops over time, following a linear or curve-linear trajectory. The intercept factor describes the initial mathematics content coverage level at the starting point of the longitudinal measurement. The slope factor describes the rate of growth for the mathematics content coverage over different measurement occasions. For both growth factors, a mean and a variance are estimated. Thus, LGCM can illustrate the average starting value and average rate of growth for all countries over all TIMSS cycles from 2003 to 2015 . However, LGCM also assumes that countries may not start their development on an equal footing, and may not either follow the 
same rate and direction of change. A variance is also estimated for the two growth factors, capturing such an assumption. More specifically, LGCM estimates the variability between subjects in the parameters that form their trajectories, namely, inter-individual differences (i.e., variance of the growth factors) in intra-individual change (i.e., mean of the growth factors). Thus, the latent growth analysis helps us in identifying the general development of curricula coverage and difference of such a general development across countries. Within a SEM framework, it is common practice to assess global model fit before interpreting estimated parameters to warrant that the specified model fits the data. We used several fit statistics to evaluate model fit, relying mostly on the model chi-square test. We also used the comparative fit index (CFI), where values around 0.90-0.95 indicate acceptable fit, and the absolute model fit index root mean square error of approximation (RMSEA), where values 0.05-0.08 show fair fit (Wang \& Wang, 2012). However, RMSEA may be less preferable when sample size is small (e.g. Hu \& Bentler, 1999).

\section{Latent profile analysis}

Latent profile analysis (LPA) is an individual-centered approach that classifies cases into homogeneous latent groups, based on the conditional probability of a set of continuous observed variables, given the latent profiles (Muthén \& Muthén, 2014). In the present article, we assume that there is unobserved heterogeneity among countries concerning the amount of content coverage in different subdomains of mathematics. LPA thus provides a means for identifying such latent profiles of countries, within which the covered math topics are generally similar. The decision as to the number of latent profiles that can be classified is based on the Bayesian Information Criterion (BIC), and an entropy value is consulted for evaluating the quality of the classification (see, for example, Schwartz, 1978). BIC is a likelihood-based criterion that penalizes particularly complex models, i.e. when many parameters are included in the model, and is often used in comparing models with varying amounts of parameters. The model with the lowest BIC is usually preferred. The entropy ranges between 0 and 1 , where higher values indicate that distinct classes have been sorted out. The substantive meaningfulness of the latent profiles must also be considered when determining the number of latent profiles. It should be emphasized that an extremely small group may be a statistical artifact that reflects only the measurement character in the sample (Samuelsen \& Dayton, 2010).

\section{Analytical procedure}

As mathematics subdomains, number, algebra, geometry and data, were measured in all TIMSS cycles. This enabled us to construct a country-level mean scale for each subdomain and each cycle. This scale represents the proportion coverage over time in each country's curricula. In a first step, these derived variables were used as indicators to study curriculum harmonization in a latent growth model. We used all subdomains in an initial step. However, due to minimal variation in the subdomain number, we excluded this from our analyses.

In the next step, we specified the number of different latent profiles and thereafter evaluated and compared the model fit. Given the available data, several hypotheses are to be tested, and which correspond to the two first research questions. First, countries may differ significantly in the mathematics content coverage at the starting point (i.e., TIMSS 2003), and this may change significantly over time. Second, countries may have a differentiated focus of their curricular content, and different homogeneous clusters of countries may be found in each TIMSS cycle (i.e., ordered by similar region, language and/or culture). Third, the same country may belong to different clusters of countries in different TIMSS cycles, thus indicating a change in their intended curriculum over time. Finally, in case of a pattern where, proceeding in time, fewer clusters are identified, this indicates a general harmonization of curricula coverage in mathematics over time in different countries.

\section{RESULTS}

To explore the development of curricula coverage, we ran a latent growth curve analysis, where we modelled the changes in the countries' average score of content coverage in subdomains of number, algebra, geometry and data over the four time-points. Using this analysis we were able to test the first hypothesis; that is addressing the question as to whether countries increase the math curriculum coverage over time. The model had an acceptable fit to the data.

As shown in Table 2, the mean variance of the intercept is significant, which implies that countries started out at a significantly different level of curricular coverage. The mean level of slope was significant, showing an increase of about .05 in curricular coverage over time. This indicates an increase in coverage of $5 \%$ between each measurement point. Since TIMSS 2003 was the baseline, the analyses indicate that the countries which also took part in later TIMSS studies tended to include more math topics in their curricula over time. However, the variance of the slope factor was not significant, which implies that countries have the same rate of growth with respect to their curricula coverage. We thus see a general pattern towards increased coverage over time, but cannot observe any convergence across countries. We therefore extended the investigation and performed a latent profile analysis. 
Table 2. Results of the latent growth curve model

\begin{tabular}{lccc}
\hline & Mean (z) & Variance (z) & Covariance (z) \\
\hline Intercept & $.74^{\star}(.03)$ & $.02^{\star *}(.009)$ & $-.005(.003)$ \\
\hline Slope & $.046^{*}(.01)$ & $.003(.002)$ & \\
\hline Model fit & & Chi-square $(\mathrm{df})=7.93(6) ; p=.24 ;$ CFI $=.92 ;$ RMSEA $=.08$ & \\
\hline Note. ${ }^{*} p<.01^{* \star} p<.05$ & & &
\end{tabular}

Table 3. Number of classes as categorized by LPA

\begin{tabular}{|c|c|c|c|c|c|c|}
\hline & No. Profiles & $\begin{array}{l}\text { No. countries in } \\
\text { each profile }\end{array}$ & Proportions & BIC & Entropy & $\begin{array}{c}p \text {-value for Vuong-Lo- } \\
\text { Mendell-Rubin test }\end{array}$ \\
\hline \multirow{2}{*}{ Model 1} & 1 & 63 & .30 & 25.307 & .894 & \multirow{2}{*}{0.001} \\
\hline & 2 & 150 & .70 & & & \\
\hline \multirow{3}{*}{ Model 2} & 1 & 44 & .21 & -282.415 & 1.000 & \multirow{3}{*}{0.0001} \\
\hline & 2 & 39 & .18 & & & \\
\hline & 3 & 130 & .61 & & & \\
\hline \multirow{4}{*}{ Model 3} & 1 & 44 & .21 & -288.505 & .975 & \multirow{4}{*}{0.1746} \\
\hline & 2 & 8 & .04 & & & \\
\hline & 3 & 39 & .18 & & & \\
\hline & 4 & 122 & .57 & & & \\
\hline
\end{tabular}

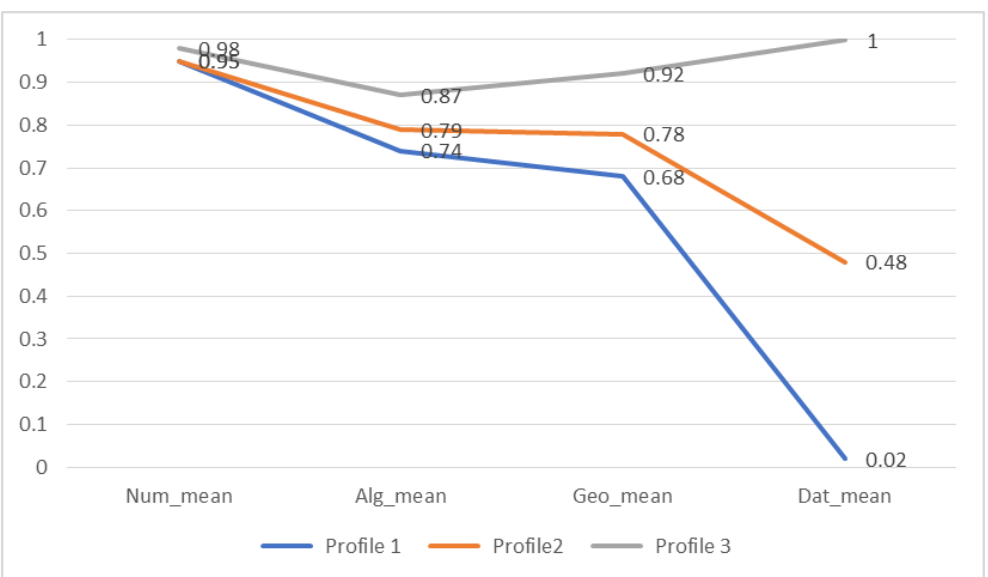

Figure 1. Mean of the indicators of content coverage in each latent profile of countries

In order to investigate the hypothesis of convergence, we ran a series of latent profile analyses using the mean content coverage of the four subdomains of mathematics. Bayesian information criteria, entropy level, and the average latent class probabilities for most likely latent class membership were all examined. The number of countries in each profile was also checked. The model solution with the lowest BIC is usually preferred. For sake of simplicity, in Table 3 we present the statistics for two, three and four profiles only.

We found the solution with three classes preferable. While the solution with four profiles had a slightly lower $\mathrm{BIC}$, the number of countries in one group was very small and the Lo-Mendell-Rubin test showed that a four class solution was not preferred over the one with three. Also, the entropy-value of 1 indicated that three classes were clearly separating the individual countries into mutually exclusive profiles, which can also be proved by the average latent class probabilities for most likely latent class membership. As regards the three class classification, no cross-classification was found (probabilities were 1 each class classification).

To highlight the differences between the three groups, their mean values are presented in Figure 1. While subdomains Number, Algebra and Geometry are of fairly equal size, subdomain Data contained a fewer number of topics (see Table 1). As may be seen, profile number 3 has the greatest coverage of mathematics topics in their curriculum. As previously noted, all three profiles have high coverage in numbers, although they differ with respect to the other three (numbers were therefore excluded in further analyses to ease computations). In subdomain Data, the largest differences among the clusters of countries can be found. In the next step, we explored which countries belonged to the different clusters, and if there were any differences between the time-points with regard to belongingness to different profiles. As shown in Table 4, we used the country ID and an ID for study (TIMSS 2003 to TIMSS 2015) to structure the profile belongingness. We thus structured the data in order to display the trend for each and every country in a comprehensive manner. To facilitate a more straightforward interpretation, we chose to focus on countries that participated three times or more in TIMSS. In Table 4, the trend in math coverage is displayed for these countries. 
Table 4. Country's profile belongingness in each TIMSS cycle based on their content coverage in subdomains of mathematics curriculum

\begin{tabular}{|c|c|c|c|c|}
\hline Country & TIMSS03 & TIMSS07 & TIMSS11 & TIMSS15 \\
\hline Armenia & 3 & 1 & 3 & 1 \\
\hline Australia & 3 & 3 & 3 & 3 \\
\hline Bahrain & 3 & 2 & 3 & 3 \\
\hline Botswana & 1 & 1 & 1 & 3 \\
\hline Canada, Ontario & 3 & 3 & 3 & 3 \\
\hline Canada, Quebec & 2 & 3 & 3 & 3 \\
\hline Chile & 2 & & 3 & 3 \\
\hline Chinese Taipei (TWN) & 1 & 2 & 1 & 1 \\
\hline Dubai, UAE & & 3 & 3 & 3 \\
\hline England & 3 & 3 & 3 & 3 \\
\hline Georgia & & 2 & 3 & 3 \\
\hline Ghana & 3 & 3 & 3 & \\
\hline Hong Kong & 2 & 3 & 3 & 2 \\
\hline Hungary & 3 & 3 & 3 & 3 \\
\hline Indonesia & 1 & 2 & 1 & \\
\hline Iran & 1 & 3 & 3 & 3 \\
\hline Israel & 3 & 2 & 3 & 2 \\
\hline Italy & 3 & 3 & 3 & 3 \\
\hline Japan & 1 & 1 & 3 & 3 \\
\hline Jordan & 2 & 2 & 3 & 3 \\
\hline Korea, Rep. of & 2 & 1 & 3 & 3 \\
\hline Lebanon & 1 & 3 & 3 & 3 \\
\hline Lithuania & 2 & 2 & 2 & 2 \\
\hline Malaysia & 2 & 1 & 1 & 2 \\
\hline Morocco & 1 & 1 & 2 & 2 \\
\hline New Zealand & 3 & 3 & 3 & 3 \\
\hline Norway & 3 & 3 & 3 & 3 \\
\hline Oman & & 3 & 3 & 3 \\
\hline Palestinian Natl auth. & 2 & 3 & 3 & \\
\hline Qatar & & 2 & 3 & 3 \\
\hline Romania & 2 & 2 & 3 & \\
\hline Russian Federation & 1 & 3 & 3 & 3 \\
\hline Saudi Arabia & 1 & 1 & 3 & 3 \\
\hline Singapore & 2 & 3 & 2 & 3 \\
\hline Slovenia & 1 & 1 & 1 & 2 \\
\hline South Africa & 1 & 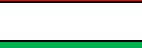 & 3 & 3 \\
\hline Sweden & 2 & 3 & 3 & 3 \\
\hline Syrian Arab Republic & 1 & 1 & 3 & \\
\hline Thailand & & 1 & 3 & 2 \\
\hline Tunisia & 1 & 1 & 2 & \\
\hline Turkey & & 2 & 3 & 3 \\
\hline United States & 3 & 3 & 3 & 3 \\
\hline
\end{tabular}

Note: number of colors represents number of profiles in each TIMSS cycle. Red $=$ Profile 1, Yellow $=$ Profile 2, and Green $=$ Profile 3

From the table, it may be noted that profile 1 and 2 are much more common in the first cycles of TIMSS, while profile 3 is more common in TIMSS 2011 and TIMSS 2015. Since profile 3 is the one with high coverage on all subdomains, this may be an indication of the fact that curriculum coverage has increased in the past few years. There tends also to be a general trend toward harmonization, in that several countries change from 2007 to 2011 , while remaining in the same profile in 2015. Looking at the pattern for Japan, Jordan, Korea, and Saudi Arabia, we may observe that all these countries changed to profile 3 in 2011 and 2015. A large number of the countries are nevertheless fairly stable with regard to their pattern of coverage across the years investigated. This holds particularly true for many "Western" countries; the United States, England, Canada, Australia, New Zealand, Italy and Norway all belong to the green profile in all TIMSS cycles. It also appears that other countries have followed these "Western" countries, since many have had large coverage from both TIMSS 2003 and TIMSS 2007. Given the fact that the curricular revisions are fairly frequent in all TIMSS assessments, the stability observed might be somewhat surprising. In Table 5, information about the proportion of countries that have ongoing curriculum 
Table 5. Proportion of countries in each TIMSS cycle having ongoing curriculum revisions

\begin{tabular}{rlrr}
\hline STUDY & $\mathbf{N}$ & Mean & .62 \\
\hline TIMSS03 & 52 & .68 \\
\hline TIMSS07 & 63 & .68 \\
\hline TIMSS11 & 57 & .57 \\
\hline TIMSS15 & 44 & \\
\hline
\end{tabular}

revision in the TIMSS cycles is presented. The proportion is based on whether or not the math curriculum is under revisions in each country and cycle. The response "Yes" was coded as 1 and "No" as 0.

As may be seen in Table 5, the mean values reveal that more than two thirds of the countries performed revisions of their curricula in TIMSS 2007 and 2011. There is however, no generally observable trend where countries increasingly revise their curricula; rather it appears as revisions in most countries are ongoing. There are naturally countries that do not revise their curricula in all cycles, although some indicated that they do. It may be noted that the character of the revisions to curricula can vary greatly between countries, with some conducting minor changes and others introducing more extensive curricula reforms. Therefore the measure used here is a rather crude one. However it is possible to use the information with regard to curricula revisions to validate previous findings. For example, we noted that Israel indicated revisions in all 4 cycles, while Sweden only revised the curriculum once, and Norway not at all. If we compare with the information in Table 5, we see that Israel indeed change their profile between all cycles, while Sweden and Norway are much more stable.

\section{DISCUSSION AND CONCLUSIONS}

Taking advantage of the information on mathematics content coverage of CQ data in all TIMSS cycles since 2003, using latent growth curve modeling techniques and latent profile analysis, the current study examined the curriculum harmonization hypothesis across countries and over time. The main finding of this article confirms the emergence of harmonized content coverage in mathematics. In the later cycles of TIMSS, there are about twice as many countries characterized by having a large curricular coverage in mathematics. The movements are in close alignment with previous finding on science curricula (e.g., Stacy et al., 2018). The finding that fewer latent profiles emerged in the recent TIMSS cycle accords well with the information provided in the TIMSS Encyclopaedia 2015, in which countries demonstrate more similarities than differences in their curricular content. In the light of these results, it needs to be acknowledged that the study focused on curriculum harmonization in relation only to the TIMSS framework, and is thus not a total measure of curriculum harmonization between countries. This is because countries are likely to have topics that are included in their mathematics curriculum that are not covered by TIMSS. Consequently, the questionnaire data does not provide a measure of the total mathematics curriculum for each country, but rather a measure expressing the correspondence between their intended mathematics curriculum, and the TIMSS framework.

A surprising result, however, was that the curricular coverage was not as high in TIMSS 2003 and TIMSS 2007, given that only about half of the items were used in 2003 compared with 2011 and 2015. If all of the curricular coverage items in 2003 and 2007 had been used, the coverage of mathematics topics in the curricula could have differed even more between the years, a finding which also points to a general trend of harmonization.

While there have been major curriculum movements in many countries, this phenomenon is particularly noticeable in the East Asian countries (see also, Leung \& Li, 2010). In Singapore, Hong Kong, Korea and Taiwan, for example, changes have been observed regarding coverage patterns. Though TIMSS strives to follow national curricula, it is likely that some countries follow TIMSS in their revisions of curricula. Consequently, certain countries might be likely to "teach to the test" to a higher degree than others. The concept of "teaching to the test" could subsume desirable, as well as undesirable behaviors (c.f., Koretz, 2002).

Even though we followed curricular trends across 12 years, there are nevertheless opportunities to extend the scope of study. In the TIMSS repeat 1999, data for NRC's should have been collected; however, "because the complex nature of the data collected with the curriculum questionnaires", these data are not available in the public release of the database (Gonzalez \& Miles, 2001, p. 3-4). In the 1995 TIMSS curricula questionnaire, the question about curricular coverage was phrased somewhat differently. Additionally, the 1995 questionnaire was very comprehensive and did not easily allow a comparison with the other years. However, we anticipate that a comparison including 1995 and 1999 would be feasible, and hope that further research will shed more light on this comparison. There is also trend data from the Programme for International Student Assessment (PISA) available, and this could be used in similar analyses, especially those with a focus on the attained curricula. PISA is likely to exert an influence on countries' curricula; it encompasses a somewhat different set of countries and ways of testing knowledge and skills. This would certainly extend knowledge regarding the globalization of curricula.

Data from NRC's are not without limitations. For some countries the NRC responses in the curriculum questionnaire may not adequately reflect the intended curriculum for the whole country. This is particularly 
obvious in the case of countries with a federal structure (like Germany) or those who are highly decentralized. Furthermore, there are likely to exist some subjectivity in the completion of the questionnaires. The mathematics topics included in the questionnaire is usually not identical to the topics listed in the different countries curricula, and, therefore, it may be difficult to achieve a perfect match to the national curricula documents across all countries.

Finally, a few notes of caution regarding assumptions about a possible causality in the current study need to be sounded. For example, curricular developments as consequence of the impact of large-scale international assessments are not easy to establish. While international studies may have large impact on educational debates and policy discussions in different countries, such effects are difficult to prove. Rather, the analyses of the current study may provide insights into curricula developments within the countries that participated in TIMSS Grade 8. Consequently, the reasons why certain developments took place need to be further established. Combining a quantitative approach, such as in the current study, with more in-depth within-country analyses, could provide a fruitful direction for future research. For example, the study might benefit from validating the findings in relation to general global and national trends in mathematics education. Such validation could, for instance, be based on the information provided in the TIMSS Encyclopaedias, and via further analyses of documents on the national curricula.

\section{ACKNOWLEDGEMENTS}

This research was supported by grants from the Swedish Research Council (Grant number 726-2013-296).

\section{REFERENCES}

Baker, B., \& LeTendre, G. (2005). National Differences, Global Similarities: World Culture and the Future of Schooling. Stanford, Calif.: Stanford University Press, 2005.

Benavot, A., Cha, Y.-K., Kamens, D., Meyer, J. W., \& Wong, S.-Y. (1991). Knowledge for the Masses: World Models and National Curricula, 1920-1986. American Sociological Review, 56(1), 85-100. https://doi.org/10.2307/2095675

Bromley, P., Meyer, J. W., \& Ramirez, F. O. (2011). Student-Centeredness in Social Science Textbooks, 1970-2008: A Cross-National Study. Social Forces, 90(2), 547-570. https:/ / doi.org/10.1093/sf/sor004

Dale, R. (1999). Specifying globalization effects on national policy: a focus on the mechanisms. Journal of Education Policy, 14(1), 1-17. https:/ / doi.org/10.1080/026809399286468

Dale, R. (2000). Globalization and education: Demonstrating a "common world educational culture" or locating a "globally structured educational agenda"? Educational Theory, 50(4), 427-448. https://doi.org/10.1111/j.1741-5446.2000.00427.x

Gonzalez, E. \& Miles, J. (2001). TIMSS 1999 User Guide for the International Database. Chestnut Hill: MA.

Gorur, R., \& Wu, M. (2014). Leaning too far? PISA, policy and Australia's 'top five' ambitions. Discourse: Studies in the Cultural Politics of Education, 1-18. https:/ / doi.org/10.1080/01596306.2014.930020

Grek, S. (2009). Governing by numbers: the PISA 'effect' in Europe. Journal of Education Policy, 24(1), 23-37. https:// doi.org/10.1080/02680930802412669

Grek, S. (2013). Expert moves: international comparative testing and the rise of expertocracy. Journal of Education Policy, 28(5), 695-709. https:// doi.org/10.1080/02680939.2012.758825

Hanushek, E. A., \& Woessmann, L. (2012). Do better schools lead to more growth? Cognitive skills, economic outcomes, and causation. Journal of Economic Growth, 17(4), 267-321. https://doi.org/10.1007/s10887-0129081-x

Hanushek, E. A., \& Woessmann, L. (2016). Knowledge capital, growth, and the East Asian miracle. Science, 351(6271), 344-345. https:// doi.org/10.1126/science.aad7796

Hegarty, S. (2014). From Opinion to Evidence in Education: Torsten Husén's Contribution. In A. Nordin \& D. Sundberg (Eds.). Transnational policy flows in European education: the making and governing of knowledge in the education policy field. Oxford, UK: Symposium books.

Hopmann, S. T., Brinek, G., \& Retzl, M. (Eds.) (2007). PISA zufolge PISA: Hält PISA, was es verspricht? / PISA according to PISA: Does PISA keep what it promises? Vienna: LIT Verlag.

Hu, L., \& Bentler, P. M. (1999). Cutoff criteria for fit indexes in covariance structure analysis: conventional versus new alternatives. Structural Equation Modeling, 6. https:/ / doi.org/10.1080/10705519909540118

Johansson, S. (2016). International large-scale assessments: what uses, what consequences? Educational Research, 58(2), 139-148. https:/ / doi.org/10.1080/00131881.2016.1165559 
Keeves, J.P. (1972). Educational environment and student achievement. Stockholm: Almqvist and Wiksell.

Komatsu, H., \& Rappleye, J. (2017). A new global policy regime founded on invalid statistics? Hanushek, Woessmann, PISA, and economic growth. Comparative Education, 53(2), 166-191. https:/ / doi.org/10.1080/03050068.2017.1300008

Koretz, D. (2002). Limitations in the Use of Achievement Tests as Measures of Educators' Productivity. Journal of human resources. https://doi.org/10.2307/3069616

Leung, F. K. S., \& Li, Y. P. (2010). Reforms and issues in school mathematics in East Asia: sharing and understanding mathematics education policies and practices. Rotterdam; Boston: Sense Publishers.

Meyer, J. W., Boli, J., Thomas, G. M., \& Ramirez, F. O. (1997). World Society and the Nation-State. American Journal of Sociology, 103(1), 144-181. https:/ / doi.org/10.1086/231174

Meyer, J.W., Kamens, D., \& Benavot, A. (1992). School knowledge for the masses: World models and national primary curricular categories in the twentieth century. London: Falmer Press.

Mullis, I. V. S., Martin, M. O., Goh, S., \& Cotter, K. (Eds.) (2016). TIMSS 2015 Encyclopedia: Education Policy and Curriculum in Mathematics and Science. Retrieved from Boston College, TIMSS \& PIRLS International Study Center website: http:/ / timssandpirls.bc.edu/timss2015/encyclopedia/

Muthén, L. K., \& Muthén, B. O. (1998-2017). Mplus user's guide (8th ed.). Los Angeles, CA: Muthén and Muthén.

Ozga, J. (2012). Governing knowledge: data, inspection and education policy in Europe. Globalisation, Societies and Education, 10(4), 439-455. https:/ / doi.org/10.1080/14767724.2012.735148

Pettersson, D. (2008) Internationell kunskapsbedömning som inslag $i$ nationell styrning av skolan. [International knowledge assessments: an element of national educational steering] Acta Universitatis Upsaliensis. Uppsala Studies in Education No 120. Uppsala universitet: Uppsala.

Phillips, D., \& Ochs, K. (2004). Researching policy borrowing: Some methodological challenges in comparative education. British Educational Research Journal, 30(6), https:/ / doi.org/10.1080/0141192042000279495

Robitaille, D.F. and Garden, R.A. (1989). The IEA study of mathematics II. Context and outcomes of school mathematics. Oxford: Pergamon.

Rutkowski, L., \& Rutkowski, D. (2009). Trends in TIMSS responses over time: evidence of global forces in education? Educational Research and Evaluation, 15(2), 137-152. https:/ / doi.org/10.1080/13803610902784352

Sahlberg, P. (2006). Education Reform for Raising Economic Competitiveness. Journal of Educational Change, 7(4), 259-287. https:// doi.org/10.1007/s10833-005-4884-6

Samuelsen, K. M., \& Dayton, M. C. 2010. Latent class analysis. In G. R. Hancock \& R. O. Mueller (Eds.), The reviewer's guide to quantitative methods in the social sciences. New York, NY: Routledge.

Schmidt, W. H., McKnight, C. C., Valverde, G. A., Houang, R. T. and Wiley, D. E. (1997). Many Visions, Many Aims: A Cross-National Investigation of Curricular Intentions in School Mathematics. Dordrecht, The Netherlands: Kluwer. https:// doi.org/10.1007/978-94-011-5786-5

Simola, H. (2005). The Finnish miracle of PISA: historical and sociological remarks on teaching and teacher education. Comparative Education, 41(4), 455-470. https:/ / doi.org/10.1080/03050060500317810

Spring, J. (2008). Research on Globalization and Education. Review of Educational Research, 78(2), $330-363$. https:/ / doi.org/10.3102/0034654308317846

Stacey, O., Lazzari, G. D., Grayson, H., Griffin, H., Jones, E., Taylor, A., \& Thomas, D. (2018). The Globalization of Science Curricula: Springer International Publishing. https:/ / doi.org/10.1007/978-3-319-71532-2

Wang, J., \& Wang, X. (2012) Structural Equation Modeling: Applications using Mplus: Methods and Applications. West Sussex, UK: Higher Education Press. https:/ / doi.org/10.1002/9781118356258

Winstanley, C. (2012). Alluring Ideas: Cherry Picking Policy from Around the World. Journal of Philosophy of Education, 46(4), 516-531. https:/ / doi.org/10.1111/j.1467-9752.2012.00876.x

Wiseman, A. W., Astiz, M. F., \& Baker, D. P. (2013). Comparative education research framed by neo-institutional theory: a review of diverse approaches and conflicting assumptions. Compare: A Journal of Comparative and International Education, 44(5), 688-709. https:/ / doi.org/10.1080/03057925.2013.800783

Zhao, Y. (2012). Flunking Innovation and Creativity. Phi Delta Kappan, 94, 56-61. https://doi.org/10.1177/003172171209400111

\section{http://www.ejmste.com}

